\title{
Epidemiology of hepatitis viruses among hepatocellular carcinoma cases and healthy people in Egypt: A systematic review and meta-analysis
}

\author{
Elizabeth M. Lehman* and Mark L. Wilson \\ Department of Epidemiology, University of Michigan, Ann Arbor, MI
}

Liver cancers are strongly linked to hepatitis B virus (HBV) and hepatitis $\mathrm{C}$ virus (HCV). Egypt has the highest prevalence of $\mathrm{HCV}$ worldwide and has rising rates of hepatocellular carcinoma (HCC). Egypt's unique nature of liver disease presents questions regarding the distribution of $\mathrm{HBV}$ and $\mathrm{HCV}$ in the etiology of HCC. Accordingly, a systematic search of MEDLINE, ISI Web of Science, ScienceDirect and World Health Organisation databases was undertaken for relevant articles regarding $\mathrm{HBV}$ and $\mathrm{HCV}$ prevalence in Egypt among healthy populations and HCC cases. We calculated weighted mean prevalences for $\mathrm{HBV}$ and $\mathrm{HCV}$ among the populations of interest and examined differences in prevalence by descriptive features, including age, year and geographic region. Prevalences for $\mathrm{HBV}$ and $\mathrm{HCV}$ were $6.7 \%$ and $13.9 \%$ among healthy populations, and $25.9 \%$ and $78.5 \%$ among HCC cases. Adults had higher prevalences of both infections (Adult $\mathrm{HBV}=\mathbf{8 . 0 \%}$, Child $\mathrm{HBV}=1.6 \%$; Adult $\mathrm{HCV}=15.7 \%$, Child HCV $=4.0 \%$ ). Geographically, HBV was higher in the south, whereas HCV was greater in the north (North HBV = $4.6 \%$, South $\mathrm{HBV}=11.7 \%$; North $\mathrm{HCV}=15.8 \%$, South $\mathrm{HCV}=$ $6.7 \%$ ). Among HCC cases, HBV significantly decreased over time $(p=0.001)$ while HCV did not, suggesting a shift in the relative influences of these viruses in HCC etiology in Egypt. Our results highlight large amounts of heterogeneity among the epidemiological factors associated with liver disease in Egypt and underscore the necessity of an integrated strategy for the successful prevention of viral hepatitis infections and chronic liver disease.

(C) 2008 Wiley-Liss, Inc.

Key words: pooled analysis; liver cancer; infectious diseases; developing countries

Hepatocellular carcinoma (HCC) comprises nearly 6\% of all incident cancer cases worldwide, with the overwhelming majority occurring in the developing world. ${ }^{1}$ One of the least curable malignancies, HCC is the third most frequent cause of cancer mortality among men worldwide. ${ }^{1}$ Chronic infection with hepatitis B virus (HBV) and hepatitis $\mathrm{C}$ virus (HCV) have been cited as, by far, the most important etiologic agents. ${ }^{2}$ According to the World Health Organisation (WHO), 350 million people are chronically infected with HBV and 170 million are infected with $\mathrm{HCV} .{ }^{3,4}$ The relative importance of $\mathrm{HBV}$ and $\mathrm{HCV}$ as causative agents can vary greatly from region to region and over time. ${ }^{1,5}$ Selecting appropriate HCC prevention and control methods, therefore, depends on understanding the dynamics of these agents in a specified geographic region.

Incidence of HCC in Egypt is currently increasing, which may be the result of a shift in the relative importance of $\mathrm{HBV}$ and $\mathrm{HCV}$ as primary risk factors. ${ }^{6-8} \mathrm{HCC}$ is the second most frequent cause of cancer incidence and mortality among men in Egypt. ${ }^{9}$ Hospitalbased studies from Egypt have reported an increase in the relative frequency of all liver-related cancers in Egypt ( $>95 \%$ as HCC), from $\sim 4.0 \%$ in 1993 to $7.3 \%$ in $2003 .{ }^{6-8}$ The Middle East Cancer Consortium recently reported that the incidence rate among males was 7 times greater than the next highest rate (among Israeli Jews) and more than 3 times that reported in the United States Surveillance Epidemiology and End Results summary. ${ }^{9}$ To explain this trend it is necessary to understand the dynamics of HBV and HCV in Egypt.

Before implementing the HBV vaccine in the 1980s, chronic infection with $\mathrm{HBV}$ was widespread and considered the dominant etiologic factor in HCC development. ${ }^{10}$ Childhood HBV immunization in Egypt today is estimated at 95-100\%, thus making it likely that HBV-related HCC will steadily decline over the next few decades. ${ }^{1,12}$ This transition is not unique to Egypt. Many eastern Mediterranean and Middle Eastern countries are experiencing a decline in HBV due to vaccination campaigns. ${ }^{13,14}$ What sets Egypt apart is that this major public health achievement has been eclipsed by the rise of the HCV epidemic, largely attributed to the mass parenteral antischistosomal therapy (PAT) and other iatrogenic exposures. ${ }^{15-18}$

Beginning in the 1950s, the Egyptian Ministry of Health targeted schistosomiasis as its primary health problem, and mounted a massive public health campaign to control it. At the time, the best control method was through injecting individuals with PAT. These campaigns were carried out at the community level as well as in health facilities, where millions of Egyptians were treated with PAT from the 1950 s until the 1980 s. $^{18}$ Needle sterilization was inadequate, and disposable needles were unavailable at that time, leading to widespread transmission of HCV. ${ }^{16,18}$ Frank et al. (2000) reported the strong relationship between PAT and countrywide prevalence of HCV antibodies for the period 1961-1985. They have cited the PAT campaign as "the world's largest iatrogenic transmission of blood-borne pathogens known to date." 16

Egypt's high levels of HCV are unique in comparison to nearby countries, even those also heavily burdened by schistosomiasis. ${ }^{16,19}$ Though these countries also used PAT to control schistosomiasis, they never mounted any public health campaigns of similar magnitude. Their control efforts were also more focused geographically and less population intensive. ${ }^{16}$ This could explain why the burden of HCV in Egypt is so much greater than the surrounding countries with similar schistosomiasis treatments.

Egypt is now plagued by the highest prevalence of HCV in the world, with estimates ranging from 6 to $28 \%$ and a reported average of $\sim 13.8 \% .^{20,21}$ Recent investigations in Egypt have also shown the increasing importance of $\mathrm{HCV}$ infection in the etiology of HCC, now estimated to account for $40-50 \%$ of cases. ${ }^{6-8}$ The future of HCC in Egypt and the magnitude of its socio-economic burden will be a legacy of the country's unique HCV epidemic and the shifting dynamics of HBV and HCV. To date, there has been no systematic review of the literature to synthesize the results of published prevalence studies, including patterns over time. There is, therefore, a need to calculate the fluctuating prevalences of HBV and HCV in Egypt over the past 2 decades among a healthy population-based sample; there is also a need to synthesize data about HCC patients, using appropriate meta-analytic tools. This paper aims to calculate weighted average prevalences of $\mathrm{HBV}$ and HCV among 2 groups in Egypt from 1985 to the

Abbreviations: Anti-HCV, hepatitis C virus antibody; $\mathrm{HBsAG}$, hepatitis $B$ virus surface antigen; HBV, hepatitis B virus; HCC, hepatocellular carcinoma; $\mathrm{HCV}$, hepatitis $\mathrm{C}$ virus; HPW, healthy pregnant women; RBD, replacement blood donors; VBD, voluntary blood donors.

Grant sponsors: Sigma Xi Grant-in-Aid of Research, University of Michigan School of Public Health (Global Health Program).

*Correspondence to: Department of Epidemiology, 109 S. Observatory, School of Public Health, University of Michigan, Ann Arbor, MI 48109-2029, USA. Fax: 734-647-2465. E-mail: lehmane@umich.edu

Received 20 May 2008; Accepted after revision 6 August 2008

DOI 10.1002/ijc.23937

Published online 30 October 2008 in Wiley InterScience (www.interscience. wiley.com). 
present: healthy, population-based samples (nonhigh risk) and incident $\mathrm{HCC}$ cases.

\section{Material and methods}

Literature search methods

MEDLINE, ISI Web of Science, ScienceDirect and WHO regional indexed databases were used to search for articles published from January 11980 to October 31 2007, by means of the $\mathrm{MeSH}$ terms of: "HCC and Egypt", "HBV and Egypt" and "HCV or hepacvirus and Egypt'. No language limitation was imposed. For HCC studies, the time and place of subject recruitment were cross-checked to avoid inclusion of the same cases in multiple articles. Articles or reports from nonpeer-reviewed sources were not considered for this analysis.

\section{Data analyzed}

The key information abstracted from each study included: (i) year(s) conducted, to account for the delay between field work and publication; (ii) sample size; (iii) age range of participants, with $\geq 18$ years considered adults; (iv) geographic region of the sample (upper or lower Egypt); $(v)$ type of residence (urban or rural); (vi) prevalence of hepatitis B surface antigen (HBsAg); (vii) prevalence of anti-HCV antibodies (anti-HCV); and (viii) type of HCV serology test used. We could not examine sex differences in HBV and HCV infection, because too few studies reported virus marker prevalence stratified by participant gender. Similarly, we could not examine HBV and HCV coinfection as it was rarely reported.

\section{Inclusion and exclusion criteria}

Healthy population-based studies included the following sample populations: ( $i$ ) voluntary blood donors (VBD); (ii) replacement blood donors (RBD) typically from friends or blood relations; (iii) healthy antenatal women; and (iv) community studies. We excluded studies from the following special groups who were assumed to be at special high risk: patients from sexually-transmitted-disease clinics, thalassemia clinics, hospitalised patients, professional or paid blood donors, sex workers, drug abusers, dialysis patients and health care workers. Healthy population-based studies with fewer than 100 participants were excluded from this analysis.

HCC studies were limited to those examining incident cases to avoid temporal ambiguity and the possibility that virus infection may have occurred subsequent to the cancer diagnosis. HCC studies with fewer than 25 participants were excluded from this analysis.

Eligible studies had to report prevalence of HBsAg and/or antiHCV. Studies were excluded if they failed to indicate the type of test used to assess infection status and if the sensitivity and specificity of the test was unknown. Information regarding $\mathrm{HBV}$ infection and immunity status can be obtained from 4 common seromarkers: $\mathrm{HBsAg}$, anti-HBs, total hepatitis B core antibody (anti-HBc) and IgM antibody to hepatitis B core antigen (IgM anti-HBc). Of these markers, only HBsAg can identify the current infection. A positive result indicates either active or chronic infection. Antibody markers cannot distinguish between naturallyacquired immunity and vaccine-related immunity. ${ }^{22}$ Since we wanted to measure the prevalence of naturally acquired infection, HBsAg was the seromarker of interest. In addition, these tests are inexpensive, simple to conduct, reliable and have been available for a long time, allowing them to be fairly standard even in lowresource settings. ${ }^{22}$

$\mathrm{HCV}$ infection status can be determined in 2 primary ways: enzyme immunoassay (EIA) or polymerase chain reaction (PCR). EIA techniques indicate the presence of antibody (anti-HCV) while PCR can serve to confirm infection as well as measure viral load. Both methods indicate ongoing infection and do not correlate well with resolved infection. As with $\mathrm{HBsAg}$, anti-HCV does not distinguish between acute and chronic infection. ${ }^{23}$ While PCR techniques tend to be more accurate, they are far more expensive and, thus, infeasible for low-resource settings or areas with higher prevalence. With a sensitivity greater than $95 \%$ and the availability of standardized test kits, the WHO recommends EIA as the primary screening tool and suggests PCR be used for clinical and case management purposes. ${ }^{23}$ For these reasons, it is rare to find PCR tests reported in the literature from lower-resource settings such as Egypt and we believe the results of EIA are sufficiently consistent and reliable to be used in this analysis. Though some studies did report both anti-HCV and PCR results, we only examined anti-HCV to limit bias due to varying test sensitivity and specificity.

In addition, studies known or likely to have used first-generation ELISA for measuring anti-HCV were not included in this meta-analysis due to known problems of sensitivity and specificity of those assays. ${ }^{24}$ To date, there have been 3 generations of antiHCV EIAs, with the first developed in 1990. It suffered from poor sensitivity and could not detect antibody prior to 4-6 months following initial infection. These tests also lacked sufficient specificity, resulting in numerous false positive results. Second and third generation tests have dramatically improved sensitivity $(>95 \%)$ and narrowed the window period between infection and anti-HCV detection. ${ }^{23}$ Consequently, this analysis only considered reports that used second or third generation anti-HCV EIAs, thereby excluding 3 studies.

We also applied specific definitions when classifying Lower and Upper Egypt as well as urban and rural settings. ${ }^{25}$ Lower and Upper Egypt are broad geographic designations that respectively refer to the north and south regions of Egypt. They are termed according to the flow of the Nile, which runs south to north. Lower Egypt is so termed, because it lies further downstream. Studies have suggested that HCV prevalence differs between Lower Egypt in the north and Upper Egypt in the south. ${ }^{6,7}$ Thus, we compared studies of these 2 regions which comprised the vast majority of published reports.

The Egyptian government classifies "governorates" (muhafazat) as either fully urban or joint urban and rural. ${ }^{25}$ The official distinction between urban and rural is reflected in the lower tiers. Fully urban governorates have no districts (markazes) which are defined as a conglomeration of villages around a capital city. In joint urban and rural governorates, therefore, urban locations are comprised of each district's capital city. All other locations in that governorate are considered rural. Some urban governorates consist of just 1 city (e.g. Cairo which has 23 urban neighborhoods). HCV prevalence differences between urban and rural populations have been suggested, so we systematically explored this hypothesis using strict and consistent definitions. ${ }^{8,15-18,26}$

\section{Statistical power}

Two types of statistical power issues exist: small participant sample size in individual studies and small sample size of studies, particularly when stratified by subfactors of analysis (e.g. geographic region, age group, etc). Pooling 30 studies with sample sizes of 50 , for example, may not be as reliable as pooling 5 studies of 300 participants. Nevertheless, it is difficult to compare multiple studies of a particular geographic region to a single study in a different region, regardless of sample size. Our sample size criteria are somewhat arbitrary, but we did base our decision on what is known about the difference in viral prevalence among healthy population samples $v s$. HCC case samples in Egypt. Since little information is available on power calculations for these biomarkers in Egypt, we took a more qualitative approach. Egypt experiences a higher burden of HBV and HCV in its apparently healthy population as compared to other countries, so we believe a minimum sample size of 100 is adequate to detect statistical differences between groups, provided the sample is a genuine representation of the entire population of interest. Sample sizes of HCC studies tend to be small because of the difficulty in obtaining participants. 
TABLE I - SUMMARY OF DATA ABSTRACTED FROM HEALTHY POPULATION LITERATURE

\begin{tabular}{|c|c|c|c|c|c|c|c|c|}
\hline Biomarker & Author [citation] & Study period & Population & Region & Residence & Age & $n$ & Prevalence $(\%)$ \\
\hline \multirow[t]{12}{*}{ HBsAg } & Sherif et al. [28] & 1983 & Community & Lower & Urban and Rural & $18+\mathrm{yr}$ & 1,064 & 11.7 \\
\hline & Sherif et al. [28] & 1983 & Community & Lower & Urban and Rural & $18+\mathrm{yr}$ & 802 & 8.0 \\
\hline & Gumie et al. [29] & 1988-1990 & VBD & Lower & Urban and Rural & $18+\mathrm{yr}$ & 1,715 & 2.5 \\
\hline & El-Sherbini et al. [30] & 1991 & School children & Lower & Urban and Rural & $<18 \mathrm{yr}$ & 198 & 1.5 \\
\hline & El-Hawey et al. [31] & 1991-1992 & Community & Lower & Rural & $18+\mathrm{yr}$ & 300 & 15.7 \\
\hline & Arthur et al. [32] & 1993 & VBD & Upper and Lower & Urban and Rural & $18+\mathrm{yr}$ & 1,030 & 12.7 \\
\hline & Mabrouk et al. [33] & 1993 & Army recruits (male) & Lower & Urban and Rural & $18+\mathrm{yr}$ & 297 & 1.7 \\
\hline & Darwish et al. [34] & 1993 & VBD & Lower & Urban and Rural & $18+\mathrm{yr}$ & 163 & 3.2 \\
\hline & Darwish et al. [35] & 1995 & Community & Lower & Urban and Rural & $18+\mathrm{yr}$ & 796 & 8.8 \\
\hline & El-Sherbini et al. [30] & 1995 & School children & Lower & Rural & $<18 \mathrm{yr}$ & 300 & 0.7 \\
\hline & Reda et al. [36] & 1997 & Community & Lower & Urban and Rural & $<18 \mathrm{yr}$ & 500 & 2.2 \\
\hline & El-Sherbini et al. [30] & 2002 & School children & Upper & Urban & $<18 \mathrm{yr}$ & 470 & 1.5 \\
\hline \multirow[t]{24}{*}{ Anti-HCV } & El-Sherbini et al. [37] & 1991 & School children & Lower & Rural & $<18 \mathrm{yr}$ & 138 & 15.9 \\
\hline & El-Sherbini et al. [37] & 1991 & School children & Lower & Urban & $<18 \mathrm{yr}$ & 130 & 6.2 \\
\hline & El-Sherbini et al. [37] & 2002 & School children & Lower & Urban & $<18 \mathrm{yr}$ & 470 & 2.1 \\
\hline & Fathalla et al. [38] & 1991-1992 & VBD & Upper and Lower & Urban and Rural & $18+\mathrm{yr}$ & 248 & 18.2 \\
\hline & Arthur et al. [32] & 1993 & VBD & Upper and Lower & Urban and Rural & $18+\mathrm{yr}$ & 2,644 & 24.8 \\
\hline & Darwish et al. [34] & 1993 & VBD & Lower & Rural & $18+\mathrm{yr}$ & 163 & 22.0 \\
\hline & El-Sherbini et al. [37] & 1994 & School children & Lower & Rural & $<18 \mathrm{yr}$ & 294 & 2.0 \\
\hline & Kumar et al. [39] & 1994-1996 & HPW & Lower & Urban and Rural & $18+\mathrm{yr}$ & 499 & 15.0 \\
\hline & Darwish et al. [35] & 1995 & Community & Lower & Urban and Rural & $18+\mathrm{yr}$ & 796 & 40.3 \\
\hline & Kassem et al. [40] & 1996 & HPW & Lower & Urban and Rural & $18+\mathrm{yr}$ & 100 & 19.0 \\
\hline & Mohamed et al. [41] & 1997 & Community & Lower & Rural & $<18 \mathrm{yr}$ & 1,823 & 8.2 \\
\hline & Mohamed et al. [41] & 1997 & Community & Upper & Rural & $<18 \mathrm{yr}$ & 2,808 & 2.5 \\
\hline & Stoszek et al. [42] & $1997-2003$ & HPW & Lower & Urban and Rural & $18+\mathrm{yr}$ & 2,587 & 15.8 \\
\hline & Abdel Aziz et al. [43] & 1999 & Community & Lower & Rural & $18+\mathrm{yr}$ & 3,999 & 24.3 \\
\hline & Nafeh et al. & 1999 & Community & Upper & Rural & $18+\mathrm{yr}$ & 6,031 & 8.7 \\
\hline & Tanaka et al. [45] & 1999 & VBD & Upper and Lower & Urban and Rural & $18+\mathrm{yr}$ & 3,608 & 8.8 \\
\hline & Rizk et al. [46] & $2000-2002$ & HPW & Lower & Urban and Rural & $18+\mathrm{yr}$ & 696 & 15.8 \\
\hline & Bakr et al. [47] & 2002 & Community & Lower & Rural & $18+\mathrm{yr}$ & 4,720 & 19.3 \\
\hline & Mohamed et al. [48] & 2002 & Community & Lower & Rural & $18+\mathrm{yr}$ & 2,425 & 18.5 \\
\hline & Arafa et al. [20] & $2002-2003$ & Community & Lower & Rural & $18+\mathrm{yr}$ & 4,020 & 11.8 \\
\hline & Raouf et al. [49] & 2002-2003 & HPW & Lower & Urban and Rural & $18+\mathrm{yr}$ & 1,832 & 10.1 \\
\hline & El-Sadawy et al. [50] & 2003 & Community & Lower & Rural & $18+\mathrm{yr}$ & 842 & 27.4 \\
\hline & El-Sadawy et al. [50] & 2003 & Community & Lower & Urban & $18+\mathrm{yr}$ & 580 & 23.4 \\
\hline & El-Raziky et al. [51] & 2004 & Community & Lower & Urban and Rural & $<18 \mathrm{yr}$ & 1,042 & 1.4 \\
\hline
\end{tabular}

VBD, voluntary blood donors; HPW, healthy pregnant women.

Total $n$ for HBsAg studies $=7,597$.

Total $n$ for anti-HCV studies $=42,457$.

Since an overwhelming majority of HCC cases in Egypt, test positive for $\mathrm{HBV}$ and/or $\mathrm{HCV}$, we believe sample sizes of 25 and greater will provide sufficient statistical power. 6 .9

\section{Meta-analysis}

Data were analyzed according to 3 different categories: HBV prevalence among healthy population-based samples, HCV prevalence among healthy population-based samples and HBV and $\mathrm{HCV}$ prevalence among incident $\mathrm{HCC}$ cases. Summary prevalence measures were calculated as averages weighted by individual study sample size, using a standard method. ${ }^{26}$ These summary measures were used to compare differences between sub-groups in aggregate, as well as over time. Chi-square tests $(\alpha=0.05)$ were performed to determine significant differences in prevalence with respect to age category (child $v s$. adult), geographic location (Upper vs. Lower Egypt), type of residence (urban vs. rural) and study period (time; treated as a continuous variable).

Sensitivity analysis did not reveal any outlier or influential prevalence estimates among the healthy population studies. One study was found to be influential in lowering the estimate of antiHCV prevalence among HCC cases (Attia et al., 1996). ${ }^{27}$ Because this study measured only anti-HCV and not HBsAg, it was controlled for when we repeated our calculations to include only those studies that measured both HBsAg and anti-HCV. We present results from both calculations here.

All manipulations and analyses were performed using SAS v 9.1.3 (SAS Institute, Cary, NC) and MetaWin v 2.0 (Sinauer Associates, Sunderland, MA).

\section{Results}

\section{Literature search results}

The initial search generated $>1,500$ potential articles which was refined to 200 relevant articles from MEDLINE $(n=107)$, WHO regional indexed databases (57), ISI Web of Science (34) and ScienceDirect (2). A hand search of the reference lists of selected articles identified a few additional relevant studies. Final results from our search yielded a total of 39 unique peer-reviewed studies meeting our inclusion/exclusion criteria. Several studies measured both HBsAg and anti-HCV and some of them also involved more than one study site, providing prevalence measures for multiple population samples. Of these studies, 25 studied healthy population-based samples and 14 were specific to HCC cases. The healthy population-based studies included 12 with HBsAg measurements and a total sample size of 7,597 and 24 with anti-HCV measurements and a total sample size of 42,457 . The 14 HCC case investigations with HBsAg and/or anti-HCV information had a total case population of 3,275 . The time periods of data varied: 1983-2002 for HBV among healthy populationbased samples, 1991-2004 for HCV studies among healthy population-based samples and 1985-2005 for HCC studies. Data abstracted from the studies are presented in Tables I, II. Results from weighted means and chi-square tests for all categories among $\mathrm{HBV}, \mathrm{HCV}$ and $\mathrm{HCC}$ are presented in Table III.

\section{HBsAg among healthy population-based samples}

Overall, the prevalence of HBsAg among healthy populationbased samples was $6.7 \%( \pm 1.4 \%)$, with no significant variation 
TABLE II - SUMMARY OF DATA ABSTRACTED FROM HCC CASE LITERATURE

\begin{tabular}{|c|c|c|c|c|c|}
\hline Author & Study period & Patient source & Study $n$ & $\mathrm{HBsAg}+(\%)$ & Anti-HCV $+(\%)$ \\
\hline Ahmed et al. [52] & 1985 & Tropical Medicine Department, Cairo University & 25 & 28.0 & - \\
\hline El-Soudani et al. [53] & 1989-1992 & Al-Azhar University & 38 & 73.7 & - \\
\hline El-Sherif et al. [54] & $1991-1992$ & Mansoura University & 30 & 30.0 & 70.0 \\
\hline El-Zayadi et al. [6] & $1992-1995$ & Cairo Liver Center & 321 & 38.6 & 85.7 \\
\hline Abdel-Wahab et al. [55] & $1992-2005$ & Medical Research Institute, Alexandria University & 1,012 & - & 79.6 \\
\hline Abdel-Wahab et al. [56] & 1993 & National Cancer Institute, Cairo & 60 & 33.3 & - \\
\hline Angelico et al. [57] & $1993-1995$ & National Cancer Institute, Cairo & 135 & 15.6 & 67.4 \\
\hline Attia et al. [27] & 1995 & Ain Shams University Hospital & 429 & - & 53.4 \\
\hline Hassan et al. [7] & $1995-1996$ & National Cancer Institute, Cairo & 33 & 15.2 & 75.8 \\
\hline Mabrouk et al. [58] & $1995-1996$ & Ain Shams University Hospital & 34 & 20.6 & 94.1 \\
\hline Yates et al. [12] & $1997-1998$ & National Cancer Institute, Cairo & 131 & 61.8 & 73.3 \\
\hline El-Zayadi et al. [59] & $1998-2002$ & Cairo Liver Center & 750 & 20.5 & 87.9 \\
\hline El-Kafrawy et al. [60] & 1999-2002 & Ain Shams University Hospital and NCI, Cairo & 41 & 2.4 & 87.8 \\
\hline Ezzat et al. [61] & $2003-2004$ & National Cancer Institute, Cairo & 236 & 7.6 & 86.4 \\
\hline
\end{tabular}

Total $n$ for all studies $=3,275$.

All studies had a mean age between 45 and 60 yrs.

TABLE III - PREVALENCE ESTIMATES AND CHI-SQUARE RESULTS FOR ALL CATEGORIES OF ANALYSIS AND COMPARISON GROUPS

\begin{tabular}{|c|c|c|c|c|c|c|}
\hline Population of analysis & Category of analysis & Comparison group & Prevalence $(\%)$ & \# Studies & Total $n$ & $\chi^{2} p$-value \\
\hline \multirow[t]{11}{*}{ HBsAg-healthy population } & \multirow[t]{2}{*}{ Age } & Adult & 8.0 & 8 & 6,129 & \multirow[t]{2}{*}{$<0.0001$} \\
\hline & & Child & 1.6 & 4 & 1,468 & \\
\hline & \multirow[t]{2}{*}{ Time (total) } & 1983-1992 & 6.9 & 5 & 4,079 & \multirow[t]{2}{*}{0.5900} \\
\hline & & 1993-1995 & 6.5 & 7 & 3,518 & \\
\hline & \multirow[t]{2}{*}{ Time (adult) } & 1983-1992 & 7.1 & 4 & 3,881 & \multirow[t]{2}{*}{0.0027} \\
\hline & & 1993-1995 & 9.3 & 4 & 2,248 & \\
\hline & \multirow[t]{3}{*}{ Time (child) } & 1991-1993 & 1.5 & 1 & 198 & \multirow[t]{3}{*}{0.8478} \\
\hline & & 1994-1997 & 1.6 & 2 & 800 & \\
\hline & & $1998-2002$ & 1.5 & 1 & 470 & \\
\hline & \multirow[t]{2}{*}{ Region (total) } & Lower Egypt & 4.6 & 10 & 5,503 & \multirow[t]{2}{*}{$<0.0001$} \\
\hline & & Upper Egypt & 11.7 & 1 & 1,064 & \\
\hline \multirow[t]{23}{*}{ Anti-HCV-healthy population } & \multirow[t]{2}{*}{ Age } & Adult & 15.7 & 17 & 35,752 & \multirow[t]{2}{*}{$<0.0001$} \\
\hline & & Child & 4.0 & 7 & 6,705 & \\
\hline & \multirow[t]{3}{*}{ Time (total) } & 1990-1994 & 21.79 & 6 & 3,579 & \multirow[t]{3}{*}{$<0.0001$} \\
\hline & & 1995-1999 & 12.45 & 8 & 19,664 & \\
\hline & & 2000-2004 & 13.54 & 9 & 16,627 & \\
\hline & \multirow[t]{3}{*}{ Time (adult) } & $1990-1994$ & 24.7 & 3 & 3,017 & \multirow[t]{3}{*}{$<0.0001$} \\
\hline & & 1995-1999 & 14.8 & 6 & 15,033 & \\
\hline & & 2000-2004 & 14.8 & 7 & 15,115 & \\
\hline & Time (child) & 1990-1994 & 6.4 & 3 & 562 & $<0.0001$ \\
\hline & & 1995-1999 & 4.8 & 2 & 4,631 & \\
\hline & & $2000-2004$ & 1.0 & 2 & 1,512 & \\
\hline & Region (total) & Lower Egypt & 15.8 & 19 & 27,118 & $<0.0001$ \\
\hline & & Upper Egypt & 6.7 & 2 & 8,839 & \\
\hline & Region (adult) & Lower Egypt & 17.6 & 16 & 23,221 & $<0.0001$ \\
\hline & & Upper Egypt & 8.7 & 1 & 6,031 & \\
\hline & Region (child) & Lower Egypt & 5.1 & 7 & 3,897 & $<0.0001$ \\
\hline & & Upper Egypt & 2.5 & 1 & 2,808 & \\
\hline & Residence (total) & Rural & 13.4 & 10 & 27,100 & $<0.0001$ \\
\hline & & Urban & 5.5 & 3 & 1,180 & \\
\hline & Residence (adult) & Rural & 15.4 & 9 & 22,037 & $<0.0001$ \\
\hline & & Urban & 8.1 & 1 & 580 & \\
\hline & Residence (child) & Rural & 4.9 & 1 & 5,063 & 0.0003 \\
\hline & & Urban & 3.0 & 2 & 600 & \\
\hline HCC Cases (All studies) & Infection prevalence & HBV & 25.9 & 12 & 1,834 & $<0.0001$ \\
\hline & & $\mathrm{HCV}$ & 78.5 & 10 & 3,140 & \\
\hline & Infection prevalence & HBV (1985-1996) & 32.7 & 8 & 676 & $<0.0001$ \\
\hline & & HCV (1991-1996) & 68.5 & 6 & 982 & \\
\hline & Infection prevalence & HBV (1997-2004) & 21.9 & 4 & 1,158 & $<0.0001$ \\
\hline & & HCV (1997-2004) & 85.9 & 4 & 1,158 & \\
\hline & HBV prevalence & $1985-1996$ & 32.7 & 8 & 676 & $<0.0001$ \\
\hline & & 1997-2004 & 21.9 & 4 & 1,158 & \\
\hline & HCV prevalence & $1991-1996$ & 68.5 & 6 & 982 & $<0.0001$ \\
\hline & & 1997-2004 & 85.9 & 4 & 1,158 & \\
\hline HCC Cases (Only studies & Infection prevalence (total) & HBV & 24.5 & 9 & 1,711 & $<0.0001$ \\
\hline measuring both HBsAg & & $\mathrm{HCV}$ & 84.1 & 9 & 1,711 & \\
\hline and anti-HCV) & Infection prevalence (1991-1996) & HBV & 30.0 & 5 & 553 & $<0.0001$ \\
\hline & & $\mathrm{HCV}$ & 80.3 & 5 & 553 & \\
\hline & Infection prevalence (1997-2004) & HBV & 21.9 & 4 & 1,158 & $<0.0001$ \\
\hline & & $\mathrm{HCV}$ & 85.9 & 4 & 1,158 & \\
\hline & HBV prevalence & 1991-1996 & 30.0 & 5 & 553 & 0.0010 \\
\hline & & 1997-2004 & 21.9 & 4 & 1,158 & \\
\hline & $\mathrm{HCV}$ prevalence & 1991-1996 & 80.3 & 5 & 553 & 0.2015 \\
\hline & & 1997-2004 & 85.9 & 4 & 1,158 & \\
\hline
\end{tabular}




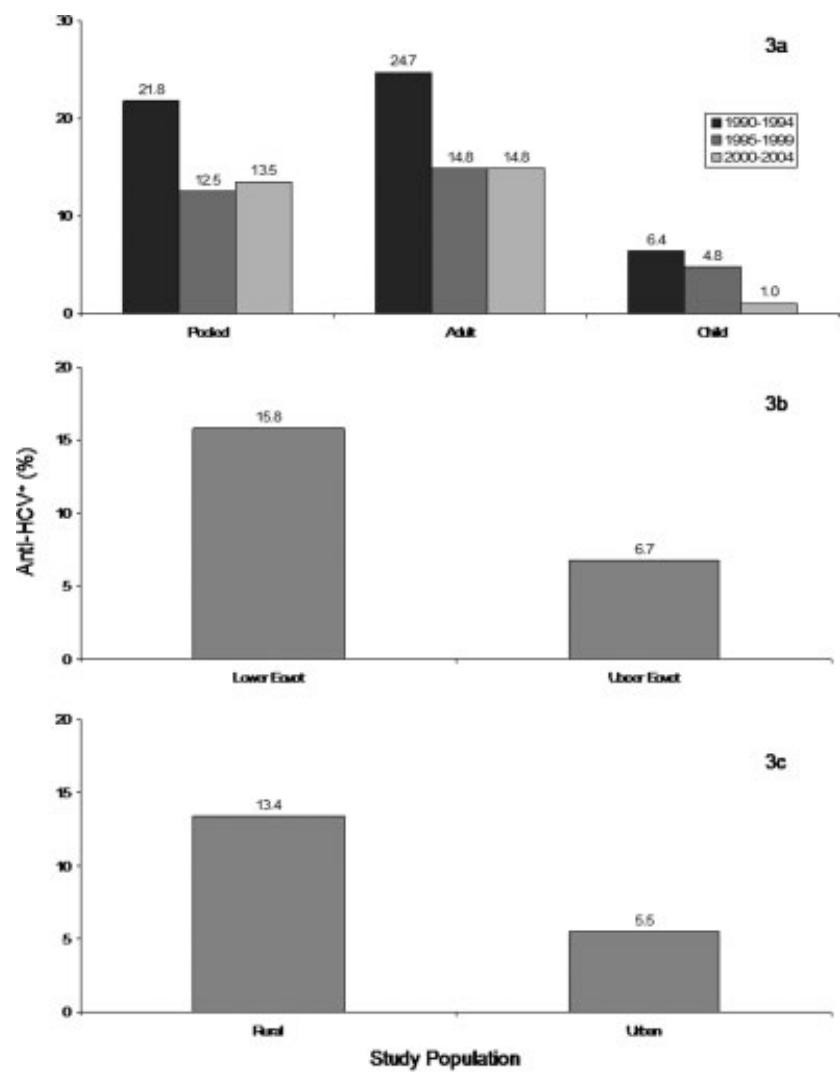

Figure 1 - Prevalence of anti-HCV + individuals. The top graph shows prevalence over 3 time periods: 1990-1994, 1995-1999 and 2000-2004. The difference observed across time period was highly significant (total, adult and child; $p<0.0001$ ). The middle graph illustrates prevalence by geographic region $(p<0.0001)$. The bottom graph shows prevalence by type of residence $(p<0.0001)$.

over time $(p=0.59)$ (Table III). When these studies were separated according to age, the pattern was similar, however, prevalence was significantly higher among adults than children $(p<$ $0.0001)$. Adults averaged a prevalence of $8.0 \%( \pm 1.7 \%)$, with children averaging at $1.6 \%( \pm 0.3 \%)$, likely a function of the introduction of the HBV vaccine.

Eleven of 12 healthy HBsAg studies provided information regarding individuals from Lower Egypt with an average prevalence of $4.6 \%( \pm 1.3 \%)$, lower than that of the Upper Egypt study $11.7 \%(p<0.0001)$. The one study from Upper Egypt may not be representative, but it was a community-based sample of 1,064 individuals.

\section{Anti-HCV among healthy population-based samples}

Table III also presents the major findings from examining the prevalence of anti-HCV among healthy population-based samples. Overall, from 1990 to 2004 the prevalence was $13.9 \%$ ( $\pm 1.6 \%$ ), also significantly higher among adults $(15.7 \% \pm 1.8 \%)$ versus children $(4.0 \% \pm 2.1 \% ; p<0.0001)$. Unlike findings with $\mathrm{HBsAg}$, however, anti-HCV prevalence seemed to vary over time, both in summary and by age group (Fig. 1; Table III). Studies from 1990 to 1994 showed a higher prevalence of $21.8( \pm 3.3 \%)$ when compared to the time periods $1995-1999(12.5 \% \pm 3.4 \%)$ and $2000-2004(13.5 \% \pm 2.0 \%)$, which were not statistically different from one another. This trend continued for adults $(p<$ $0.0001)$, but child studies suggested a continuing decline in prevalence $(p<0.0001$; Fig. 1).

Analysis of anti-HCV by geographic region found the reverse trend from what was observed with HBsAg (Fig. 1). Of the 24

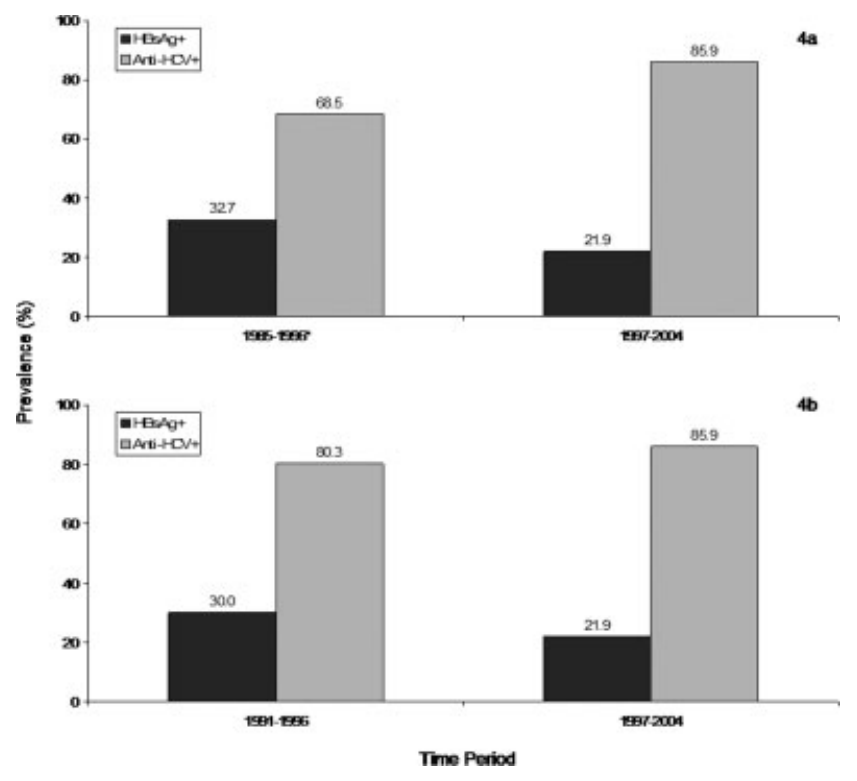

Figure 2 - Prevalence of HBsAg and anti-HCV + among HCC cases. The top graph shows prevalence over the 2 time periods: 19851996 and 1997-2004. Differences across biomarkers as well as within biomarkers over time were significant $(p<0.0001)$. The bottom graph presents prevalence over the 2 time periods: 1991-1996 and 19972004, using only studies that reported both HBsAg and anti-HCV measurements. Differences between $\mathrm{HBsAg}$ and anti-HCV were significant $(p<0.0001)$, as were differences within HBsAg prevalence over time $(p=0.001)$ but time differences within anti-HCV were not significant $(p=0.2051)$.

total studies, 19 had specific information on Lower Egypt and 2 had specific measurements for Upper Egypt. Studies from Lower Egypt showed a significantly higher prevalence $(15.8 \% \pm 1.8 \%)$ than those from Upper Egypt $(6.7 \% \pm 2.9 \%)(p<0.0001)$, a pattern that remained stratifying by age group (Table III).

We compared studies of urban $(n=3)$ and rural $(n=10)$ populations. As the literature has suggested, there was a significantly higher prevalence of anti-HCV among rural populations $(13.4 \% \pm$ $2.3 \%)$ compared to urban populations $(5.5 \% \pm 2.0 \%)(p<$ $0.0001)$. Again, this trend remained highly significant after stratifying by age group (Table III).

\section{HBsAg and anti-HCV among HCC cases}

Finally, Table III presents findings on the prevalence of $\mathrm{HBsAg}$ and anti-HCV among HCC cases. There were 12 studies with HBsAg data covering the time period 1985-2004 and 11 studies with anti-HCV measurements spanning 1991-2004. The overall prevalence of $\mathrm{HBsAg}$ was $25.9 \%( \pm 4.7 \%)$ and that of anti-HCV was $78.5 \%( \pm 3.6 \%)$, a statistically significant difference $(p<$ $0.0001)$. Both markers showed highly significant changes over time, with HBsAg decreasing (1985-1996: $32.7 \% \pm 5.2 \%$; $1997-$ 2004: $21.9 \% \pm 8.9 \% ; p<0.0001)$ and anti-HCV increasing (1991-1996: $68.5 \% \pm 6.6 \%$; 1997-2004: $85.9 \% \pm 2.6 \% ; p<$ 0.0001) over time (Fig. 2).

Of the HCC studies included, $9(n=1711)$ reported both HBsAg and anti-HCV measurements. The above analysis for these 9 studies was repeated to reduce the possibility of bias due to early generation ELISA tests, but results were similar. The overall prevalence of HBsAg was $24.5 \%( \pm 5.1 \%)$ and that of anti-HCV was $84.1 \%( \pm 2.4 \%)$. The decrease in HBsAg remained significant (1991-1996: 30.0\% \pm 5.3\%; 1997-2004: $21.9 \% \pm 8.9 \% ; p=$ 0.001). A slight increase in anti-HCV prevalence was observed for the revised group of studies, but it was no longer significant 
(1991-1996: 80.3\% \pm 4.3\%; 1997-2004: 85.9\% $\pm 2.6 \% ; p=$ 0.2015) (Fig. 2).

\section{Discussion}

This is the first systematic review and meta-analysis of hepatitis $\mathrm{B}$ and $\mathrm{C}$ virus prevalence in Egypt and provides insights for understanding the past and future dynamics of liver disease there. For $\mathrm{HBV}$ and HCV in healthy population-based samples, adults had a significantly higher prevalence than children, supporting an independent age cohort effect for both viruses. For HBV, it seems likely that the cohort effect would be related to the introduction of the hepatitis B vaccine in 1992, which was incorporated into the expanded programme on immunization and is only given to children, leaving adults unvaccinated at the time of program implementation. This explains the discrepancy in prevalence between adults and children in our analysis. It should be noted that childhood HBV studies do not begin appearing until the vaccine program had been introduced, as they were designed to evaluate the vaccine's success. Therefore, we were not able to compare childhood HBV prevalence between unvaccinated and vaccinated groups, nor were we able to find reports of adult and child prevalence in the same individual study. Based on the timing of the studies and the large difference in prevalence between adults and children, however, it seems logical to conclude that the vaccine is responsible for the consistently low levels of HBV in children and higher prevalence among the unvaccinated adults.

The cohort effect seen in HCV is consistent with other studies that report higher prevalences in age groups older than $30 \mathrm{yrs} .^{8,15-17}$ These studies were focused on identifying risk factors for $\mathrm{HCV}$ infection and often did not present prevalence results conducive for use in the meta-analysis, which is why they were not included. The age cohort observation is likely related to the early association between the parenteral antischistosomiasis therapy (PAT) campaign and HCV transmission. Oral therapies for schistosomiasis were gradually adopted in the 1980 's, dramatically reducing transmission. ${ }^{16,62}$ It is still unclear, however, what the rate of $\mathrm{HCV}$ transmission is presently, in the absence of the original primary route. Since several of the childhood HCV studies were late enough that none of the children would have been exposed to the PAT campaign, it does appear that HCV has continued to be transmitted. It will be important to understand the emerging routes and rates of transmission to effectively control the burden of liver disease in Egypt.

Our analysis confirmed reports of large scale geographic heterogeneity in HCV prevalence. ${ }^{6,7}$ We found prevalence to be significantly higher in Lower Egypt as opposed to Upper Egypt, which in turn supports the hypothesis of PAT as the dominant force driving the HCV epidemic. Individuals living in Lower Egypt experienced a greater burden of schistosomiasis and therefore a greater level of exposure to PAT. ${ }^{6,7}$ This is consistent with the only study we found directly comparing HCV prevalence in a Lower Egypt village and an Upper Egypt village (both rural). Mohamed et al. (2006) conducted a childhood study in 1997, reporting a prevalence of $8.2 \%$ in Lower Egypt and $2.5 \%$ in Upper Egypt. ${ }^{48}$ This is a slightly larger disparity than what the pooled analysis revealed (Lower Egypt: 5.1\%; Upper Egypt: 2.5\%), but this does not necessarily indicate inconsistency. Our results are unadjusted for year to prevent over-stratification, whereas these findings were from the same time period. Since we observed decreasing prevalence among children over time and our analysis included data through 2002 , we would expect the pooled result to be lower. We would also expect greater variance in our estimates since we are pooling studies from multiple, different study sites.

This is in contrast to what we saw with HBV, which seemed to be higher in Upper Egypt versus Lower Egypt. Unfortunately, the number studies of HBV prevalence in Upper Egypt was inadequate and we were unable to find any studies specifically comparing HBV in Upper and Lower Egypt, so it is best not to draw too many conclusions from that analysis.
We were also able to examine the relationship of $\mathrm{HCV}$ with urban and rural populations, with results supporting the hypothesis that $\mathrm{HCV}$ prevalence is higher among rural residents than urban residents. ${ }^{8,15,63}$ Sherbini et al. (2006) examined HCV prevalence among children in an urban setting in 1991 and 2002 and in a rural setting in 1991 and 1994. The results indicated a higher HCV prevalence in the rural region both times. In 1991, urban children had a $\mathrm{HCV}$ prevalence of $6.2 \%$ while rural children experienced a prevalence of $15.9 \%{ }^{30}$ Again, in 1994, Sherbini et al. reported a prevalence of $5.8 \%$ in the rural setting and $2.1 \%$ in the 2002 urban study. ${ }^{30}$ This trend is consistent with our results. We found a large disparity among adults, with a prevalence of $15.4 \%$ and urban prevalence of $8.1 \%$. This corresponds with the 1991 studies and that age cohort would all be adults at the time of more recent studies. The difference in rural and urban HCV prevalence was less pronounced in the pooled estimates for children (rural: $4.9 \%$; urban: $3.0 \%$ ). Again, this is logical considering the documented decrease in HCV prevalence over time among children. Sherbini et al. unfortunately do not have rural estimates more recent than 1994, making a direct comparison difficult. Nevertheless, the trend observed in the Sherbini et al. study is supportive of our pooled estimates. This finding is also in line with the PAT hypothesis; that rural residents would have a greater burden of schistosomiasis and therefore greater exposure to PAT. ${ }^{15-17,63}$

We were only able to find one childhood study that directly examined HBV in urban and rural settings. Sherbini et al. (2007) compared measurements from a 1995 study in a rural village with a 2002 study in an urban setting (both in Lower Egypt). They found a prevalence of $1.9 \%$ in the rural village and $1.1 \%$ in the urban city, which were not statistically different from one another. ${ }^{37}$ Because this was the only study to explicitly identify separate urban and rural prevalences, we did not include it in the meta-analysis. The finding is not surprising, however, since both studies were conducted after the establishment of the HBV vaccination program. The time difference between the 2 studies (rural: 1994; urban: 2002) could explain why the rural prevalence is slightly higher. The vaccine program had only been in place for a couple of years, so some unvaccinated children may have been included.

Since most of the HCC studies were hospital-based, it is difficult to speculate on future effects even though more HCC cases would be expected in rural regions. This is contrary to a recent population-based HCC study from Lower Egypt that found cases to be nearly twice as likely to come from urban versus rural areas. ${ }^{64}$ Due to the significant lag time between viral infection and development of HCC, it is possible that Egypt is witnessing the end of a cohort of higher urban exposure that will soon transition to a population dominated by rural exposure.

It was illuminating to examine the trends in $\mathrm{HBV}$ and $\mathrm{HCV}$ prevalence over the past 20 years. We did see a slight increase over time in HBV prevalence among adults from 7.1 to $9.3 \%$. It is likely that this may also be a product of the PAT campaign. The same number of people were infected with HBV and HCV during the PAT campaign; however, HBV only caused chronic infections in $\sim 5 \%$ of infected individuals, whereas chronic HCV infection developed in 70 to $80 \% .^{16,18}$ This can be explained by the natural history of HBV, where the probability of developing chronic infection decreases with age. ${ }^{10}$ Since most individuals receiving PAT were 10-15 years or older, they were at less risk for developing persistent HBV infection. ${ }^{18}$ This could explain why we saw an increase in HBV prevalence in the healthy population without a similar increase among HCC cases. Among children, however, HBV prevalence was low, probably due to the implementation of earlier control measures followed by the vaccine. Infection levels in children suggest that this infection may soon be an insignificant element of the liver disease burden in Egypt.

Unlike HBV, prevalence of HCV showed greater variance over time. Among both children and adults there was a general decline 
in prevalence over time, with adults stabilizing at just below $15 \%$ and children continuing to drop to nearly $1 \%$ by the period 2000 2004. Detailed risk factor data are needed to further characterize if time and space interactions are occurring and distinguish between the effects of population migration, changing risk factor patterns, etc. It would also be valuable to match these prevalence figures with incidence studies to reconstruct the different epidemic curves, shedding light on viral dynamics and guiding predictions about future trends in infection.

A summary understanding of the status of HBV and HCV prevalence in healthy population-based samples should be complimented by viral dynamics among HCC cases. Frequently the burden of HBV and HCV cannot easily be quantified apart from its chronic sequelae. By understanding the degree to which these viruses contribute to $\mathrm{HCC}$, it is possible to see the impact they have on overall population health. The overall prevalence of HBV among HCC cases was nearly $25 \%$, with HCV infection prevalence as high as $84 \%$. Some differences were noted over time although not statistically significant, possibly a result of low power. It seemed that HBV infection declined from a prevalence of 30\% between 1991 and 1996 to 22\% between 1997 and 2004 . Conversely, HCV infection among HCC cases may have increased slightly over this same time period from 80 to $86 \%$. This is consistent with the impact of the 2 different cohort effects. Current cancer cases represent individuals being exposed to these viruses 20-30 years prior. These cases may represent the individuals at the end of the pre-HBV vaccine period and the beginning of the PAT campaign. Based on anticipated demographic changes, it seems likely that prevalence of $\mathrm{HBV}$ will continue to decline and $\mathrm{HCV}$ will continue to increase among HCC cases for the next few decades. Indeed, results from mathematical models designed to predict the future burden of HCV in Egypt are consistent with this hypothesis. ${ }^{63}$ What happens after that will depend largely on the new HCV incidence patterns in the absence of the PAT campaign.

Despite our extensive literature search, the specific search terms used may not have captured all quality papers published in peerreviewed indexed journals. For this reason, we supplemented our electronic search by a hand search of references from selected articles, but there is always the possibility that some studies were missed. We attempted to gain representative samples of the Egyptian healthy population by accepting community-based samples, but also included some large scale convenience samples such as healthy pregnant women attending clinics and VBD. The inclusion of VBD in systematic reviews has been questioned in a study at Vellore, India where the HBV carrier rate was $0.7 \%$, considered artificially low because donors are a self-selected group and HBV-positive people do not repeat donations. ${ }^{65}$ However, another analysis of different population groups tested in Delhi, found voluntary donors, replacement donors and ante-natal mothers all had prevalences close to the overall mean. ${ }^{66}$ The extent to which the HCC cases we reported upon are representative is also unclear, since in most cases only hospital-based studies were available. We did focus on cancer studies from the larger, nationally recognized cancer centers, which serve as diagnostic and treatment facilities for the overwhelming majority of cancer cases throughout Egypt.

Only a large, national epidemiological study can provide a definitive answer regarding the overall prevalence of hepatitis B and C viruses in Egypt. Lacking such a national sample survey, our systematic review and meta-analysis of high quality studies previously conducted provides a useful compromise. These findings highlight the significance of continuing prevention of $\mathrm{HBV}$ through vaccination campaigns as well as the development of an integrated strategy for the prevention of $\mathrm{HCV}$ infection that should include screening of blood donations, safe injection practices and avoidance of unnecessary injections. Controlling transmission of these 2 viruses should effectively reduce the burden of HCC in Egypt.

\section{Acknowledgements}

The authors would like to thank Drs. R.P. Beasley, S.K. Murray, and Z. Yang for their insightful comments and critical feedback regarding statistical methods interpretation of results for this analysis. The authors would also like to thank the members of the Gharbiah Cancer Registry in Tanta, Egypt, particularly Drs. H. El-Hamzawy, A. Hablas, K. Ismail, M. Ramadan, and I. Seifeldin for their help in contextualizing the results from this study. E.M. Lehman was supported by a US National Science Foundation Graduate Research Fellowship and a Sigma Xi Grant-in-Aid of Research. Both E.M. Lehman and M.L. Wilson were supported by the Global Health Program at the University of Michigan School of Public Health.

\section{References}

1. Parkin DM, Bray F, Ferlay J, Pisani P. Global cancer statistics, 2002. CA Cancer J Clin 2005;55:74-108.

2. IARC. Monographs on the evaluation of carcinogenic risks to humans. vol.59. Lyon: International Agency for Research on Cancer, 1994.

3. WHO. Hepatitis B vaccines. Wkly Epidemiol Rec 2004;79:263.

4. WHO and the Viral Hepatitis Prevention Board. Global surveillance and control of hepatitis C. Report of a WHO consultation organized in collaboration with the viral hepatitis prevention board, Antwerp, Belgium. J Viral Hepat 1999;6:35-47.

5. Yu MC, Yuan JM, Govindarajan S, Ross RK. Epidemiology of hepatocellular carcinoma. Can J Gastroenterol 2000;14:703-9.

6. El-Zayadi AR, Badran HM, Barakat EM, Attia Mel-D, Shawky S, Mohamed MK, Selim O, Saeid A. Hepatocellular carcinoma in Egypt: a single center study over a decade. World J Gastroenterol 2005;11: 5193-8.

7. Hassan MM, Zaghloul AS, El-Serag HB, Soliman O, Patt YZ, Chappell CL, Beasley RP, Hwang LY. The role of hepatitis C in hepatocellular carcinoma: a case control study among Egyptian patients. J Clin Gastroenterol 2001:33:123-6.

8. Strickland GT, Elhefni H, Salman T, Waked I, Abdel-Hamid M, Mikhail NN, Esmat G, Fix A. Role of hepatitis C infection in chronic liver disease in Egypt. Am J Trop Med Hyg 2002;67:43642.

9. Freedman LS, Edwards BK, Ries LAG, Young JL, eds. Cancer incidence in four member countries (Cyprus, Egypt, Israel, and Jordan) of the middle east cancer consortium (MECC) compared with US SEER. National Cancer Institute. Bethesda, MD: NIH Pub. No. 06-5873, 2006.

10. Beasley RP. Hepatitis B virus. The major etiology of hepatocellular carcinoma. Cancer 1988;61:1942-56.
11. Khella AK, Faris L, Helmy S, Yosif A, Esmail S. Hepatocellular carcinoma; characteristics and possible etiologies in a group of Egyptian patients. J Egypt Public Health Assoc 1992;67:741-52.

12. Yates SC, Hafez M, Beld M, Lukashov VV, Hassan Z, Carboni G, Khaled H, McMorrow M, Attia M, Goudsmit J. Hepatocellular carcinoma in Egyptians with and without a history of hepatitis B virus infection: association with hepatitis $\mathrm{C}$ virus $(\mathrm{HCV})$ infection but not with HCV RNA level. Am J Trop Med Hyg 1999;60:714-20.

13. Alavian SM, Fallahian F, Lankarani KB. The changing epidemiology of viral hepatitis B in Iran. J Gastointestin Liver Dis 2007;16:4036.

14. Toukan AU. Hepatitis B in the Middle East: aspects of epidemiology and liver disease after infection. Gut 1996;38 (Suppl 2):S2-S4.

15. Halim AB, Garry RF, Dash S, Gerber MA. Effect of schistosomiasis and hepatitis on liver disease. Am J Trop Med Hyg 1999;60:91520.

16. Frank C, Mohamed MK, Strickland GT, Lavanchy D, Arthur RR, Magder LS, El Khoby T, Abdel-Wahab Y, Aly Ohn ES, Anwar W, Sallam I. The role of parenteral antischistosomal therapy in the spread of hepatitis C virus in Egypt. Lancet 2000;355:887-91.

17. El-Zayadi AR. Curse of schistosomiasis on Egyptian liver. World J Gastroenterol 2004;10:1079-81.

18. Strickland GT. Liver disease in Egypt: hepatitis C superseded schistosomiasis as a result of iatrogenic and biological factors. Hepatology 2006;43:915-22

19. Sharara AI, Ramia S, Ramlawi F, Fares JE, Klayme S, Naman R. Genotypes of hepatitis $\mathrm{C}$ virus (HCV) among positive Lebanese patients: comparison of data with that from other middle Eastern countries. Epidemiol Infect 2007;135:427-32.

20. Arafa N, El Hoseiny M, Rekacewicz C, Bakr I, El-Kafrawy S, El Daly M, Aoun S, Marzouk D, Mohamed MK, Fontanet A. Changing 
pattern of hepatitis $\mathrm{C}$ virus spread in rural areas of Egypt. J Hepatol 2005;43:418-24.

21. El Gaafary MM, Rekacewicz C, Abdel-Rahman AG, Allam MF, El Hosseiny M, Hamid MA, Colombani F, Sultan Y, El-Aidy S, Fontanet A, Mohamed MK. Surveillance of acute hepatitis C in Cairo, Egypt. J Med Virol 2005;76:520-5.

22. WHO. Hepatitis B surface antigen assays: operational characteristics (Phase I). Report 1. Geneva: World Health Organisation, 2001.

23. WHO. Hepatitis C assays: operational characteristics (Phase II). Report 2. Geneva: World Health Organisation, 2001.

24. Booth JC, O'Grady J, Neuberger J. Clinical guidelines on the management of hepatitis C. Gut 2001;49 (Suppl 1):I1-I21.

25. Central Agency for Public Mobilization and Statistics. Statistical year book. Cairo, Egypt: CAPMAS, 2005.

26. Reijnders J, Ehrt U, Weber WEJ, Aarsland D, Leentjens AFG. A systematic review of prevalence studies of depression in Parkinson's disease. Mov Disord 2008;23:183-9.

27. Attia MAM, Zekri ARN, Goudsmit J, Boom R, Khaled HM, Mansour MT, de Wolf F, el-Din HM, Sol CJ. Diverse patterns of recognition of hepatitis $\mathrm{C}$ virus core and nonstructural antigens by antibodies present in Egyptian cancer patients and blood donors. J Clin Microbiol 1996;34:2665-9.

28. Sherif MM, Abou-Aita BAS, Abou-Elew MH, El-Kafrawi A. Hepatitis B virus infection in upper and lower Egypt. J Med Virol 1985; $15: 129-35$.

29. Gumie MAB, Tawfik Ali TM. A sero survey for hepatitis B, syphilis and human immuno deficiency virus antibodies among blood donors and recipients. New Egyp J Med 1990;4:973-6.

30. El Sherbini A, Mohsen SA, Seleem Z, Ghany AA, Moneib A, Abaza AH. Hepatitis B virus among schoolchildren in an endemic area in Egypt over a decade: impact of hepatitis B vaccine. Am J Infect Control 2006;34:600-2.

31. El Hawey AM, Abdel Hafez MA, Ibrahim MS, Ahmed GN, Hebisha MA. Hepatitis B virus markers in schistosomiasis patients in a village in Menoufia governorate. Egypt, and their response to Praziquantel. New Egypt J Med 1993;8:1206-10.

32. Arthur RR, Hassan NF, Abdallah MY, El-Sharkawy MS, Saad MD, Hackbart BG, Imam IZ. Hepatitis C antibody prevalence in blood donors in different governorates in Egypt Trans R Soc Trop Med Hyg 1997;91:271-4.

33. Mabrouk MA, Abdel-Rahim AY, Zakaria S, El-Garem A. The low frequency of hepatitis B virus infection in schistosomal and nonschistosomal Egyptian army recruits. New Egypt J Med 1994; 10:2263-7.

34. Darwish MA, Raouf TA, Rushdy P, Constantine NT, Rao MR, Edelman R. Risk factors associated with a high seroprevalence of hepatitis $\mathrm{C}$ virus infection in Egyptian blood donors. Am J Trop Med Hyg 1993;49:440-7.

35. Darwish MA, Faris R, Darwish N, Shouman A, Gadallah M, El-Sharkawy MS, Edelman R, Grumbach K, Rao MR, Clemens JD. Hepatitis $\mathrm{C}$ and cirrhotic liver disease in the Nile delta of Egypt: a communitybased study. Am J Trop Med Hyg 2001;64:147-53.

36. Reda AA, Arafa MA, Youssry AA, Wandan EH, Ab de Ati M, Daebees $\mathrm{H}$. Epidemiologic evaluation of the immunity against hepatitis B in Alexandria. Egypt Eur J Epidemiol 2003;18:1007-11.

37. El Sherbini A, Mohsen SA, Hasan W, Mostafa S, El Gohary K, Moneib A, Abaza AH. The peak impact of an Egyptian outbreak of hepatitis C virus: has it passed or not yet occurred? Liver Int 2007;27:876-7.

38. Fathalla SES. Hepatitis C infection among Egyptian blood donors in the eastern Saudi Arabia with/without past history of schistosomiasis. Arch STD HIV Res 1994;8:71-5.

39. Kumar RM, Frossad PM, Hughes PF. Seroprevalence and mother-toinfant transmission of hepatitis $\mathrm{C}$ in asymptomatic Egyptian women. Eur J Obstet Gynecol Reprod Biol 1997;75:177-82.

40. Kassem AS, El-Nawawy AA, Massoud MN, Abou El-Nazar SY, Sobhi EM. Prevalence of hepatitis C virus (HCV) infection and its vertical transmission in Egyptian pregnant women and their newborns. J Trop Pediatr 2000;46:231-3.

41. Mohamed MK, Magder LS, Abdel-Hamid M, El-Daly M, Mikhail NN, Abdel-Aziz F, Medhat A, Thiers V, Strickland GT. Transmission of hepatitis $\mathrm{C}$ virus between parents and children. Am J Trop Med Hyg 2006; 75:16-20.

42. Stoszek SK, Abdel-Hamid M, Narooz S, El Daly M, Saleh DA, Mikhail N, Kassem E, Hawash Y, El Kafrawy S, Said A, El Batanony M, Shebl FM, et al. Prevalence of and risk factors for hepatitis $\mathrm{C}$ in rural pregnant Egyptian women. Trans R Soc Trop Med Hyg 2006;100:102-7.

43. Abdel-Aziz F, Habib M, Mohamed MK, Abdel-Hamid M, Gamil F, Madkour S, Mikhail NN, Thomas D, Fix AD, Strickland GT, Anwar W, Sallam I. Hepatitis C virus (HCV) infection in a community in the Nile Delta: population description and HCV prevalence. Hepatology 2000;32:111-5.
44. Nafeh MA, Medhat A, Shehata M, Mikhail NNH, Swifee Y, AbdelHamid M, Watts S, Fix AD, Strickland GT, Anwar W, Sallam I. Hepatitis $\mathrm{C}$ in a community in upper Egypt: I. Cross-sectional survey. Am J Trop Med Hyg 2000;63:236-41.

45. Tanaka Y, Agha S, Saudy N, Kurbanov F, Orito E, Kato T, Abo-Zeid M, Khalaf M, Miyakawa Y, Mizokami M. Exponential spread of hepatitis C virus genotype 4a in Egypt. J Mol Evol 2004;58:191-5.

46. Rizk MAH, Osman MI, Gaafar TM, Elawady SAA, Abdel-Hameed O. Hepatitis $\mathrm{C}$ virus infection among Egyptian pregnant women and its mother to infant transmission: a prospective study. New Egypt J Med 2002;27:162-72.

47. Bakr I, Rekacewicz C, El Hosseiny M, Ismail S, El Daly M, ElKafrawy S, Esmat G, Hamid MA, Mohamed MK, Fontanet A. Higher clearance of hepatitis $\mathrm{C}$ virus infection in females compared with males. Gut 2006;55:1183-7.

48. Mohamed MK, Bakr I, El-Hoseiny M, Arafa N, Hassan A, Ismail S, Anwar M, Attala M, Rekacewicz C, Zalata K, Abdel-Hamid M, Esmat G, et al. HCV-related morbidity in a rural community of Egypt. J Med Virol 2006;78:1185-9.

49. Raouf AA, Hosney M, Omer A, El Gammal T, El Sebai H, Zayd IS, Abdel-Sattar L. Hepatitis C virus (HCV) in pregnancy: prevalence and risk factors for infection. Al. Azhar Med J 2004;33:235-48.

50. El-Sadawy M, Ragab H, El-Toukhy H, El-Mor AEL, Mangoud AM, Eissa MH, Afefy AF, el-Shorbagy E, Ibrahem IA, Mahrous S, AbdelMonem A, Sabee EI, et al. Hepatitis C virus infection at Sharkia governorate. Egypt: seroprevalence and associated risk factors. J Egypt Soc Parasitol 2004;34:367-84.

51. El-Raziky MS, El-Hawary M, Esmat G, Abouzied AM, El-Koofy N, Mohsen N, Mansour S, Shaheen A, Abdel Hamid M, El-Karaksy H. Prevalence and risk factors of asymptomatic hepatitis $\mathrm{C}$ virus infection in Egyptian children. World J Gastroenterol 2007;13:1828-32.

52. Ahmed L, El-Rooby AS, Rarrag A, Salama Z. Prevalence of hepatitis $B$ virus in patients suffering from primary hepatocellular carcinoma. J Egypt Med Assoc 1986;69:363-71.

53. El-Soudani S. Study on the role of schistosomiasis and hepatitis in the development of hepatocellular carcinoma. New Egypt J Med 1993; 8:1604-7.

54. El-Sherif MZ, El-Kannishy MH, Ali AA, Ramadan F, Amra HA. Primary hepatocellular carcinoma and aflatoxicosis. New Egypt J Med 1993;8:1633-40.

55. Abdel-Wahab MF, Zakaria S, El Kady N, Omar A, Zakaria E, Milad M. Important risk factors related to hepatocellular carcinoma in Egypt. New Egypt J Med 1994;10:2276-81.

56. Abdel-Wahab M, El-Ghawalby N, Mostafa M, Sultan A, El-Sadany M, Fathy O, Salah T, Ezzat F. Epidemiology of hepatocellular carcinoma in lower Egypt, Mansoura Gastroenterology Center. Hepatogastroenterology 2007;54:157-62.

57. Angelico M, Renganathan E, Gandin C, Fathy M, Profili MC, Refai W, De Santis A, Nagi A, Amin G, Capocaccia L, Callea F, Rapicetta $\mathrm{M}$, et al. Chronic liver disease in the Alexandria governorate. Egypt: contribution of schistosomiasis and hepatitis virus infections. J Hepatol 1997; $26: 236-43$.

58. Mabrouk GM. Prevalence of hepatitis $\mathrm{C}$ infection and schistosomiasis in Egyptian patients with hepatocellular carcinoma. Dis Markers 1997; 13:177-82.

59. El-Zayadi AR, Abaza H, Shawky S, Mohamed MK, Selim OE Badran HM. Prevalence and epidemiological features of hepatocellular carcinoma in Egypt-A single center experience. Hepatol Res 2001;19:170-9.

60. El-Kafrawy SA, Abdel-Hamid M, El-Daly M, Nada O, Ismail A Ezzat S, Abdel-Latif S, Abdel-Hamid A, Shields PG, Loffredo C. p53 mutations in hepatocellular carcinoma patients in Egypt. Int J Hyg Environ Health 2005;208:263-70.

61. Ezzat S, Abdel-Hamid M, Eissa SA, Mokhtar N, Labib NA, El Ghorory L, Mikhail NN, Abdel-Hamid A, Hifnawy T, Strickland GT, Loffredo CA. Associations of pesticides. HCV, HBV, and hepatocellular carcinoma in Egypt. Int J Hyg Environ Health 2005;208:329-39.

62. Lohiniva AL, Talaat M, Bodenschatz C, Kandeel A, El-Adawy M, Earhart K, Mahoney FJ. Therapeutic injections in the context of Egyptian culture. Promot Educ 2005;12:13-8.

63. Deuffic-Burban S, Mohamed MK, Larouze B, Carrat F, Valleron AJ Expected increase in hepatitis C-related mortality in Egypt due to pre2000 infections. J Hepatol 2006;44:455-61.

64. Lehman EM, Soliman AS, Ismail K, Hablas A, Seifeldin IA, Ramadan M, El-Hamzawy H, Shoushtari CS, Wilson ML. Patterns of hepatocellular carcinoma incidence in Egypt from a population-based cancer registry. Hepatol Res 2008;38:465-73.

65. John TJ, Abraham P. Hepatitis B in India: a review of disease epidemiology. Indian Pediatr 2001;38:1318-22.

66. Batham A, Narula D, Toteja T, Sreenivas V, Puliyel JM. Systematic review and meta analysis of prevalence of hepatitis B in India. Indian Pediatr 2007;44:663-75. 